\title{
HYDRAULIC PERFORMANCE OF SYPHONS UNDER CONTROLL BY INLET AND OUTLET PIPE CUTTING ANGLES
}

Mohamed A. Awad, Gamal M. Abd-elaal, Mohamed N. Salem, Magdy H. Mowafy

\begin{abstract}
This study aims to improve the hydraulic performance of pipe siphon. An inlet and different outlet cutting i used to control the flow through the pipe and to minimize losses resulting from the sudden contraction of $t$ Experimental works were carried out using rectangular circulating flume and pipe syphon model. The pipe constant cutting angle of $(\square 1=15 \square)$ anticlockwise from the vertical axis of. The pipe outlet model had diff, angles of ( $\square 2=0 \square, 15 \square, 30 \square, 45 \square$, and $60 \square$ ) clockwise from the vertical axis of the pipe outlet. The pipe $s$ tested using different discharges $(\mathrm{Q}=7.28$ to 57.20 lit. / $\mathrm{sec}$ ) and different downstream submergence ratic $0.0,0.25,0.50,0.75$, and 1.0$)$. Dimensional analysis was employed to get the inter-relationships among $t$ factors affecting the head losses through the syphon. The results of the study led to ( $\square 1=60 \square$ ) with submt $(\mathrm{Hd} / \mathrm{D}=0.0$ and 0.25$)$ gives best results for losses and upstream water depth, while The outlet cutting an $(\square 1=30 \square$ ) with a downstream submerged ratios of ( Hd/D $=0.50,0.75$, and 1.00$)$ gives best results for los upstream water depth
\end{abstract}

